\title{
Cogan's microcystic dystrophy of the cornea: ultrastructure and photomicroscopy
}

\author{
ANTHONY J. DARK \\ From the Veterans Administration Hospital, and State University of New York Upstate Medical Center, \\ Syracuse, New York, USA
}

SUMMARY Corneal biopsy specimens from 3 patients with Cogan's microcystic corneal dystrophy were examined by light and electron microscopy. Specimens were taken from corneas showing microcysts, geographic or map-like areas, and refractile striae. In all samples there is a bilaminate subepithelial layer of fibrogranular material, the friability of which is probably the basis for recurrent erosions in this disorder. Histochemical and ultrastructural findings provide further evidence that Cogan's dystrophy, the finger print/bleb dystrophy, and Meesmann's dystrophy should be regarded as separate entities.

In their original account of microcystic dystrophy Cogan et al. (1964) noted bilateral white dots, about 0.1 to $0.05 \mathrm{~mm}$ wide, within the corneal epithelium of 5 unrelated patients. The presumably spontaneous appearance of these dots in adult life, together with the absence of inflammatory signs, naturally suggested an abiotrophic basis for the disorder. In the following year Guerry (1965) supplemented Cogan and colleagues' description by noting that the dots were accompanied by relucent, often subtle, maplike or 'geographic' nebulae which lay anterior to Bowman's membrane. These map-like patches are in fact the essential biomicroscopic feature of this condition, since they are often present without microcysts. In the same year Bietti's (1965) 'lacunar dystrophy' was apparently an independent account of the same disorder. There is general agreement that the dots, and to some extent the map areas, are in a constant state of flux, disappearing or new ones spontaneously appearing often within a few days. Support for a dystrophic aetiology was provided by Laibson and Krachmer (1975), whose studies show familial incidences suggesting autosomal dominance. Although many patients with this disorder are asymptomatic, others experience annoying symptoms either of epithelial breakdown or, if the opacities lie in the central cornea, of irregular astigmatism and diffraction.

The pathological basis of the map areas seems to

Address for reprints: Dr Anthony J. Dark, Department of Ophthalmology, Veterans Administration Hospital, Syracuse, New York 13210, USA be the deposition of an abnormal sheet of fibrogranular material which lies at the epithelial level. The microcysts were shown by Cogan and his co-workers (1964) to represent degenerating cells which are surrounded but not engulfed by their neighbours. In these and other respects there are undoubted resemblances between Cogan's dystrophy and the fingerprint/bleb dystrophy described by Bron and Brown (1971). Hence Laibson (1976) considered that the two conditions are essentially variants, though ultrastructural evidence of this contention is fragmentary.

The fine structure of the corneal epithelium in 3 patients with Cogan's microcystic dystrophy is the basis of the present study, in which its pathogenesis and relationship to other superficial dystrophies featuring epithelial microcysts is discussed.

\section{Case reports}

CASE 1

A white woman aged 58 years was found to have impaired vision in both eyes associated with bilateral posterior subcapsular cataracts. An intermittent sensation as of a foreign body had been present in both eyes for several months. Irritation of one or other eye accompanied by watering and photophobia would occur at any time of the day and last several hours. The slit-lamp microscope revealed map-like areas in the epithelial layer of both corneas. They were associated with numerous white microcysts on the left side. The map areas were best seen in the oblique broad beam as greyish relucent 


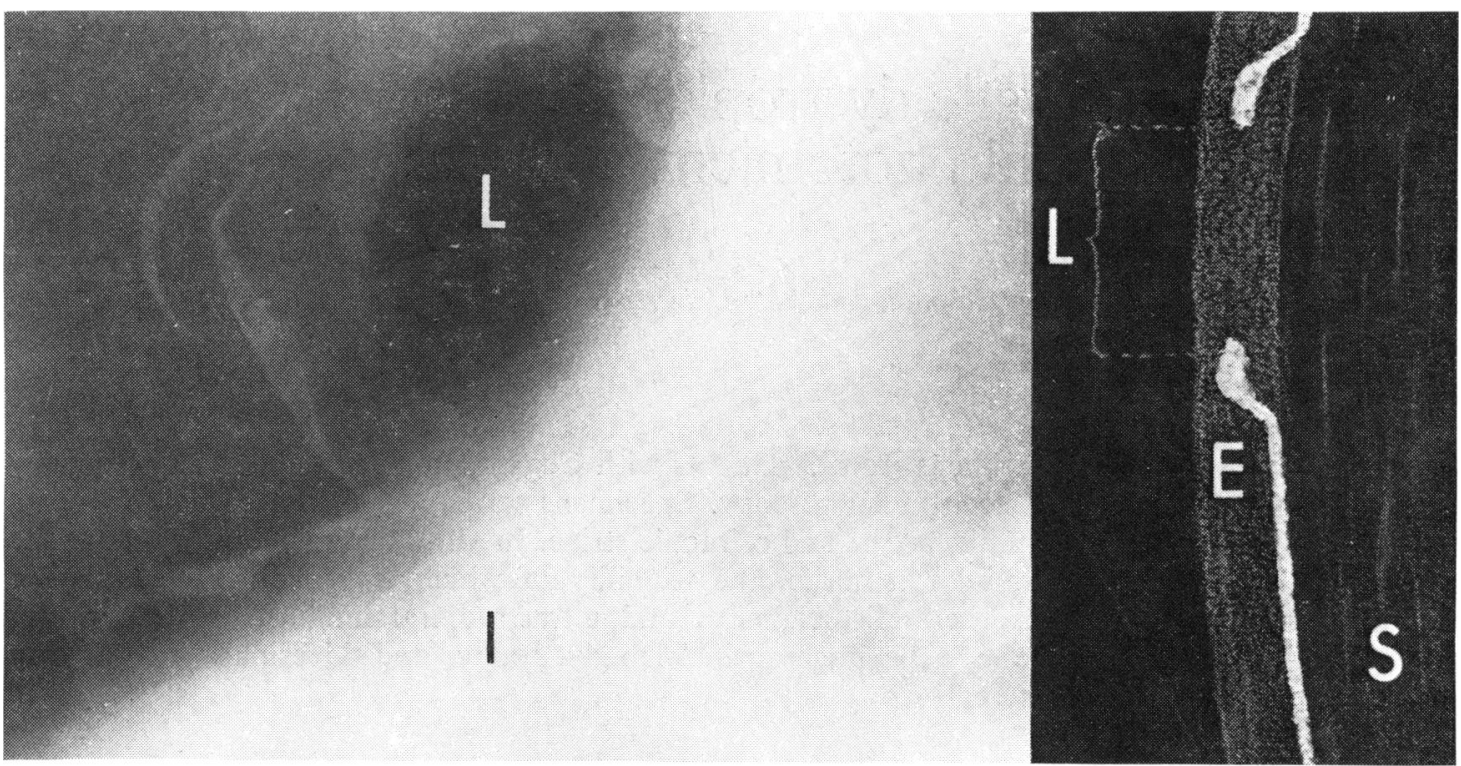

Fig. 1 Biomicroscopic appearance of 'map' nebulae in pupillary zone. Illumination by oblique light and from iris, I. Lacuna, L, and rolled edges of map material are displayed. $\times 3$. Inset, drawing of optical section of this area,

$\mathrm{E}$, epithelium; $\mathrm{S}$, stroma $\times 70$

patches irregular in shape and often perforated by round holes a millimetre or so wide (Fig. 1). Details of such a hiatus shown in Fig. 1 underwent no photographically documented change over a 4month period. The edges of these lacunae were sharply defined and in places seemed rolled over, an appearance which, as noted by Laibson (1976), is reminiscent of the capsular dehiscences seen in 'pseudoexfoliative' disease of the lens. The curled edge was refractile in retroillumination both from the iris and if viewed with the ophthalmoscope against the fundal reflex, when it appeared as a black line. In optical section a bright seam underlies the epithelium and coincides with the map areas. Near the lacunae this seam enters the epithelial band obliquely and terminates, becoming thicker at its free end, where it corresponds with the rolled edge (Fig. 1, inset). In both corneas fine refractile lines were seen by retroillumination from the iris. They differed from those seen in fingerprint dystrophy in that they could also be seen in the direct or focal slit-lamp beam, wherein they were visible as greyish lines. None of these features showed any staining with fluorescein, rose bengal, alcian blue, or iodonitrotetrazolium. The fluorescein-stained tear film rapidly broke up over the refractile striae and over the rolled edge of the geographic patches, probably indicating relative elevation of the corneal surface at these points. Moreover, massaging the cornea through the closed lid resulted in well- defined pools of fluorescein corresponding with these structures. The anterior corneal mosaic was intact. Corneal sensation to No. 7 nylon was unimpaired.

Since removal of the left cataract was indicated, preliminary debridement of the affected corneal epithelium was undertaken 2 months before operation. The regenerated epithelium, although showing new map areas, was free of microcysts, and symptoms of irritation improved. An uneventful left cataract extraction was performed with resultant $20 / 20$ vision. The ablated corneal epithelium and the cataractous lens were placed in fixatives appropriate for subsequent microscopy.

CASE 2

A 40-year-old white woman developed familial cataracts which 3 years ago had advanced to the point when left lens extraction was successfully undertaken. Since then a soft contact lens had been comfortably worn and provided her with 20/20 vision. For the past few years, however, recurrent irritation of the right eye had been accompanied by redness and photophobia. Slit-lamp examination of both corneas showed geographic patches with rolled edges characteristic of Cogan's microcystic dystrophy and with staining characteristics similar to those in Case 1. One or two microcysts were found sporadically in both corneas. A few grey lines resembling those seen in fingerprint dystrophy were 
Fig. 2 Corneal epithelium. Microcysts, $\mathrm{M}$, lie near rolled edge of midepithelial lamina, $\mathrm{L}$. Epithelial cells in this region appear distorted by the laminal edge. Toluidine blue $\times 760$

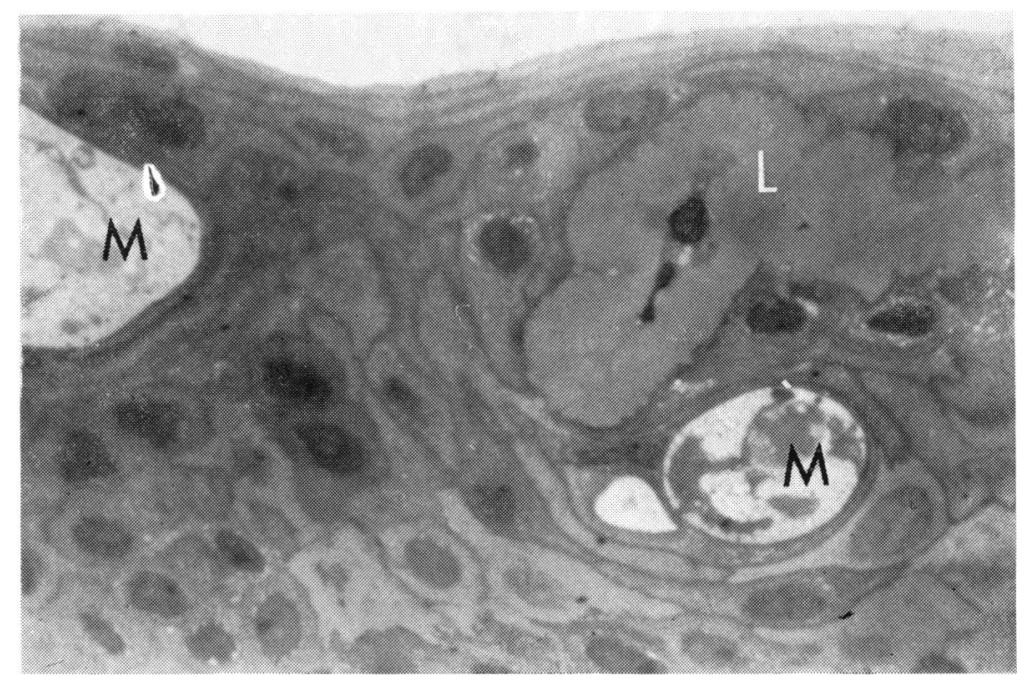

present in each cornea; they were visible in both focal and reversed light. Irritation of the right eye continued in spite of the liberal use of bland ointments, so that limited curettage of the corneal epithelium was undertaken. This was followed by less frequent attacks. The ablated epithelium was preserved for microscopy.

CASE 3

A white woman aged 60 was found to have corrected visual acuities of $O D=20 / 30$ and $O S=20 / 20$. There had been no symptoms suggestive of recurrent epithelial breakdown. Geographic patches of Cogan's microcystic dystrophy as described above were present in both corneas. There were no microcysts but 1 or 2 sheaves of fine grey lines were seen in focal light. A 2-mm trephine was used to obtain an epithelial biopsy from the pupillary zone of the right cornea. Recovery was uneventful, and vision on the right side improved by 1 line.

\section{Methods}

Corneal epithelial biopsies from Cases 1 and 2 were fixed in $10 \%$ neutral formalin, dehydrated, and then infiltrated with paraffin wax. Paraffin sections were treated with various staining techniques to be mentioned alongside the results.

Other corneal epithelial specimens from all 3 patients were fixed in $2 \frac{1}{2} \%$ cold glutaraldehyde prior to osmification and embedding in epoxy resin. Pieces of the cataractous lens obtained from Case 1 were fixed in $10 \%$ neutral formalin, osmified, and embedded in epoxy resin. Orientational sections were stained with toluidine blue and examined with the light microscope while suitably thin sections were stained with uranyl acetate and lead citrate before being submitted to transmission electron microscopy with a Phillips 300 electron microscope.

\section{Observations}

\section{LIGHT MICROSCOPY}

The lens from Case 1 showed changes consistent with posterior subcapsular cataract. There were no abnormal periodic acid Schiff (PAS) positive accumulations in relation to the lens capsule. Corneal specimens from the 3 patients consisted of epithelium basement membrane and a subepithelial layer of 'hyaline' material. Vacuolar degeneration of the epithelial cells together with acantholytic isolation of individual cells was seen in some sections.

The subepithelial seam was lightly stained pink in haematoxylin and eosin, and although otherwise structureless consisted of a more densely stained superficial layer and a paler deep layer. In places the superficial layer of this seam was insinuated between the epithelial cells and lay at a variable depth as a horizontal lamina between the surface and basal cells. In some areas this lamina was apparently ruptured. The broken ends, which were coiled, suggesting elasticity (Fig. 2), apparently corresponded with the rolled edges of the lacunae seen with the slit lamp (Fig. 1 inset). There was some distortion of the epithelial cells near the rolled edges (Fig. 2), giving the impression that it was conditioning their forward migration. Elsewhere continuity of the midepithelial lamina was maintained until it finally rejoined the subepithelial seam; the epithelial enclave thus isolated contained the majority of the microcysts.

The subepithelial and midepithelial seams were 


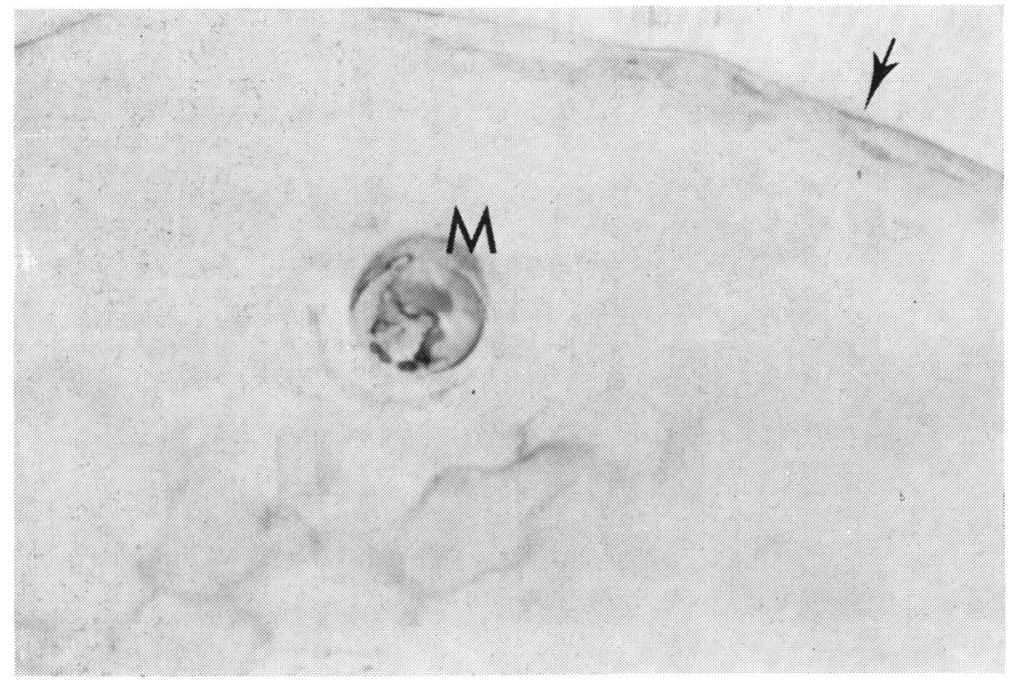

Fig. 3 Corneal epithelium. Microcyst, M, surface squames (arrowed), and nearby cell interfaces are stained with alcian blue $\times 1070$
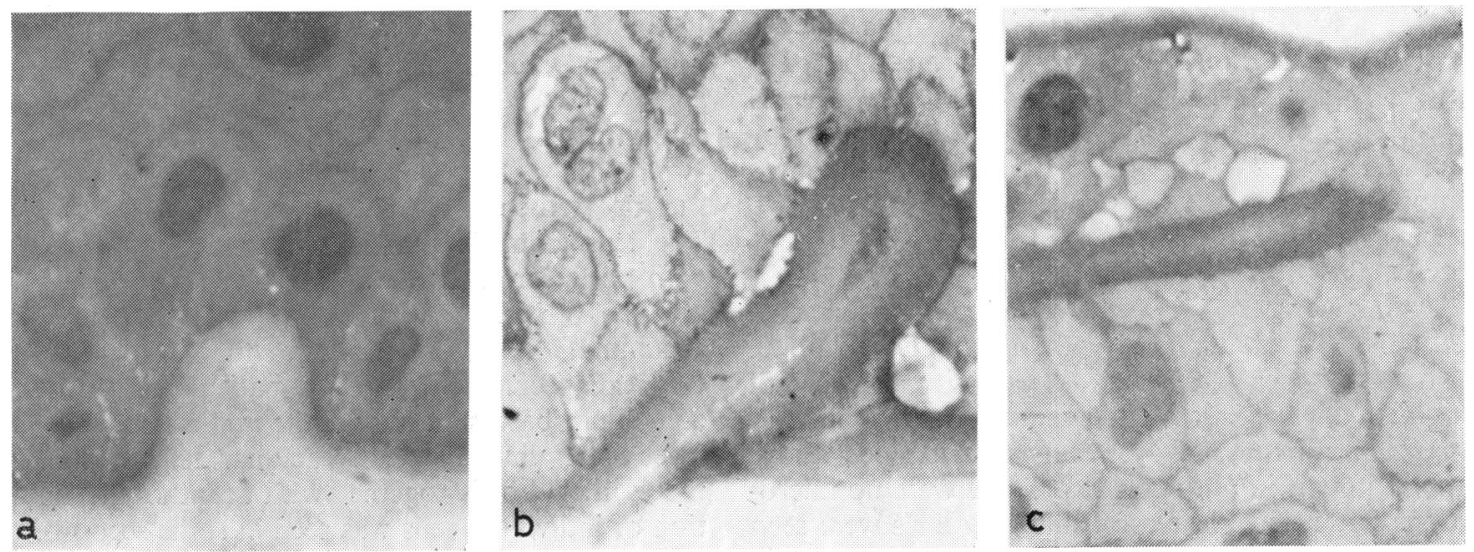

Fig. 4 Corneal epithelium to show possible pathogenesis of refractile striae. (a) Minimal folding of bilaminar subepithelial membrane. (b) Oblique invagination of similar fold into the epithelium. (c) Horizontal extensions correspond with striae, their duality is still evident. Toluidine blue $\times 1100$

strongly PAS positive but did not stain with alcian blue or Gomori's reticulin stain. They were monorefringent in polarised light and did not exhibit autofluorescence in ultraviolet light.

Microcysts contained fragmented cell debris which was often PAS positive and invariably stained with alcian blue at pH 2.5 (Fig. 3) and with colloidal iron. The lining surface of the microcysts was regularly stained with alcian blue, colloidal iron, and with Gomori's method for alkaline phosphatase in a manner similar to the anterior corneal surface. Cell borders in the vicinity of the microcysts were often sharply outlined with alcian blue and colloidal iron. Pretreatment of paraffin sections with hyaluronidase or diastase did not prevent or diminish colouration with PAS, alcian blue, or colloidal iron in any of the above structures. In general, the microcysts lay posterior to the midepithelial lamina, but a few lay close to the surface near the ruptured curled-up ends of this structure.

The refractile striae were apparently produced by invagination of the subepithelial seam, a process in which both layers were involved (Fig. 4).

\section{TRANSMISSION ELECTRON MICROSCOPY}

Epithelial cells for the most part appeared to be healthy but in places, especially posterior to the midepithelial lamina, varying degrees of hydropic degeneration were seen to result in cytoplasmic pallor. This change was accompanied by acantholy- 
Fig. 5 Corneal epithelium, 'pale' cells, showing acantholysis, A, with intercellular accumulation of granular material $\times 3600$
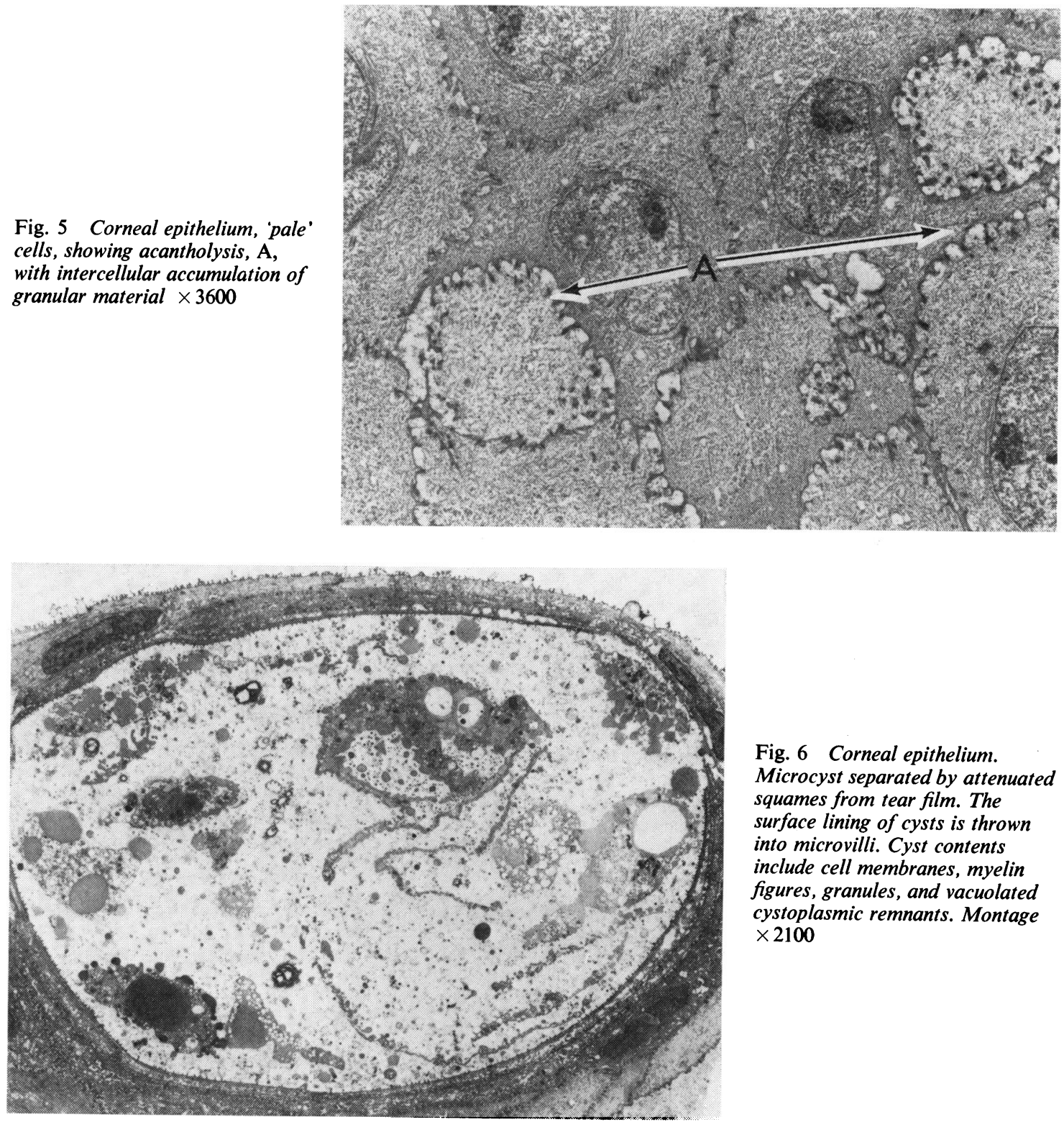

Fig. 6 Corneal epithelium. Microcyst separated by attenuated squames from tear film. The surface lining of cysts is thrown into microvilli. Cyst contents include cell membranes, myelin figures, granules, and vacuolated cystoplasmic remnants. Montage $\times 2100$

sis (Fig. 5) with the formation of amorphous granules in the widened interspace, and was presumably followed by cell shrinkage and microcyst formation. Occasionally the basal cells showed fine cytoplasmic processes extending into the subepithelial seam.

Microcysts contained a variety of cell fragments including myelin figures and cell membranes, but organelles were rarely recognisable (Fig. 6). The cell membranes surrounding these cysts were thrown into microvilli similar to those of the surface squames. The midepithelial lamina (Fig. 7) consisted mainly of irregularly banded fibres embedded in granular material similar to the superficial layer of the subepithelial seam with which it was continuous. Basement membrane and hemidesmosomes were sparse. The refractile striae were seen as interepithelial protrusions of both layers of the subepithelial layer and appeared to be produced by folding of this membrane. Basement membrane and 


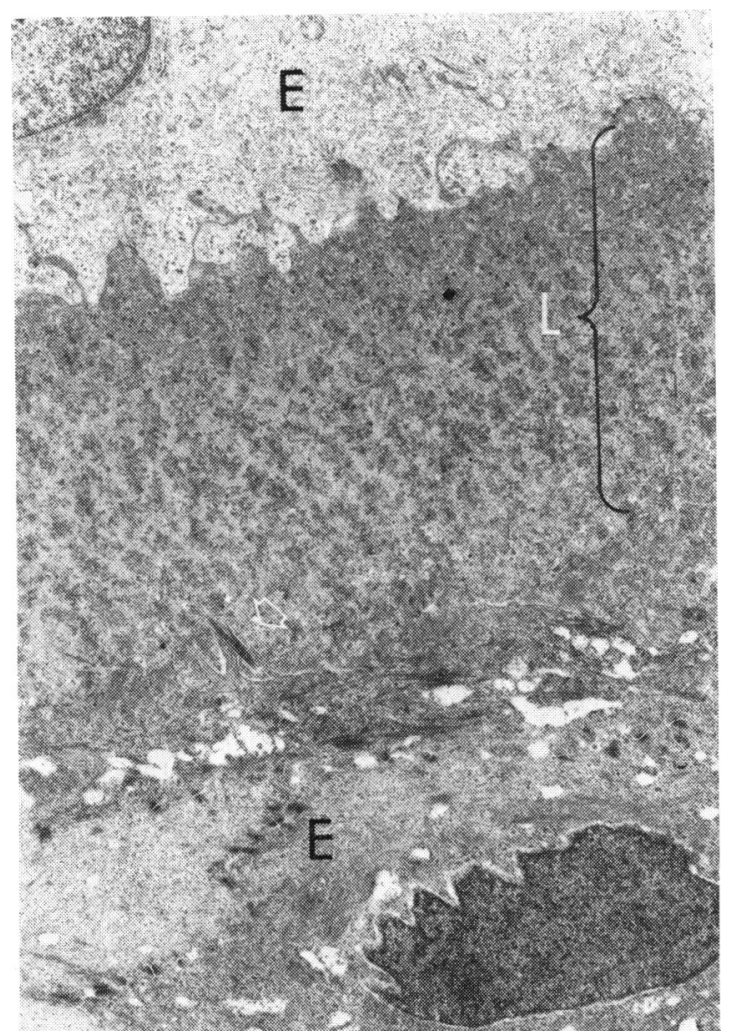

Fig. 7 Corneal epithelium, E, contains midepithelial lamina, L, composed of irregularly banded fibres, embedded in granular matrix producing a dappled effect. Basal lamina and hemidesmosomes sparsely present. Occasional collagen-like fibrils (arrowed) lie alongside $\mathrm{L} \times 4270$ hemidesmosomes were sporadically present in these infoldings.

The subepithelial seam in all specimens as noted in light microscopy was bilaminate (Fig. 8). A basement membrane was often present and appeared to have its normal complement of hemidesmosomes, but there were places where both elements were absent. The superficial layer consisted of granular material which was intimately connected to the hemidesmosomes (Fig. 9). This material formed a honeycomb-like system of compartments in which lay fibres, some $50 \mathrm{~nm}$ long. They were composed of laterally aggregated fibrils $8 \mathrm{~nm}$ wide which fanned out in three dimensions at both ends (Figs. $10,11)$. The deeper layer was mostly composed of randomly orientated fibrils banded at $28 \mathrm{~nm}$ (Fig. 12). They had a dense outer rim and rarefied core when seen in cross-section. Coarser fibrils banded at $66 \mathrm{~nm}$ like typical collagen were occasionally interspersed among the finer fibrils (Fig. 13). In some places the deep layer was composed partly of granules measuring about $7 \mathrm{~nm}$.

\section{Discussion}

The pathogenesis of Cogan's microcystic dystrophy has recently been discussed by Cogan et al. (1974) and by Rodrigues et al. (1974). Both groups consider that the microcysts, which are usually found posterior to a midepithelial lamina of presumed aberrant basement membrane material, develop because the forward migration of epithelial cells is now mechanically inhibited by this lamina. Thus trapped, the deeper cells undergo changes in situ

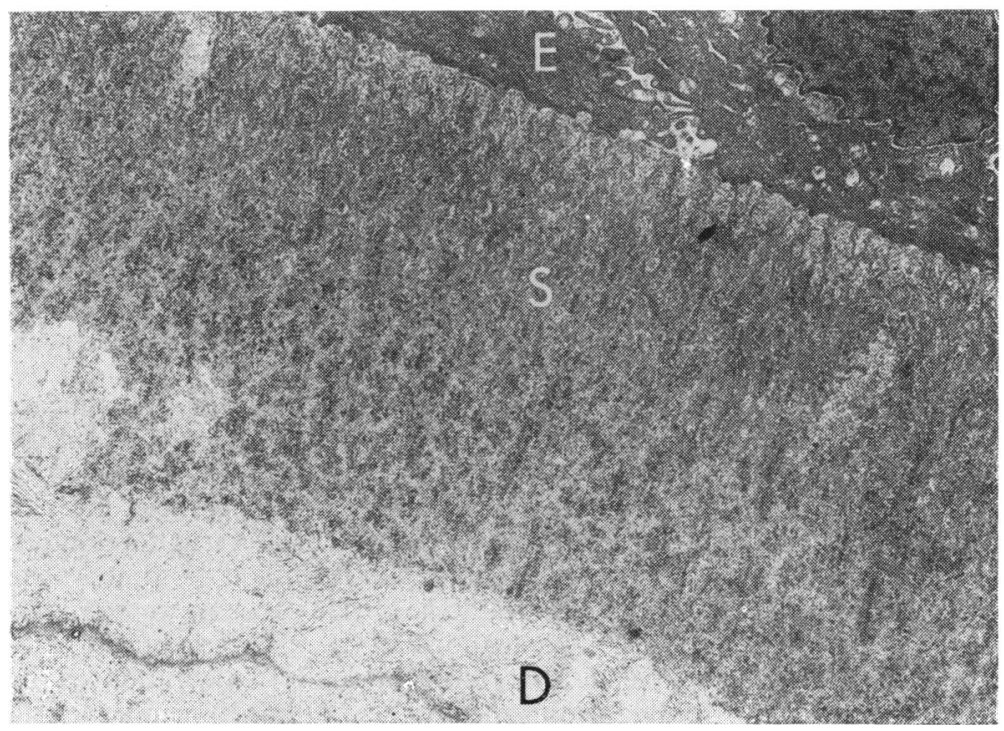

Fig. 8 Bilaminate seam lies underneath epithelium, $\mathrm{E}$, and consists of 2 layers: a superficial stratum, $\mathbf{S}$, in which darkly stained fibres are embedded in finely granular matrix, which itself is in continuity with hemidesmosomes; and deep layer, $\mathrm{D}$, which is less densely packed and contains finer randomly orientated fibrils $\times 3780$ 
Fig. 9 Illustrates continuity of basement membrane-like granular material of the superficial layer with hemidesmosomes (arrowed) $\times 46500$

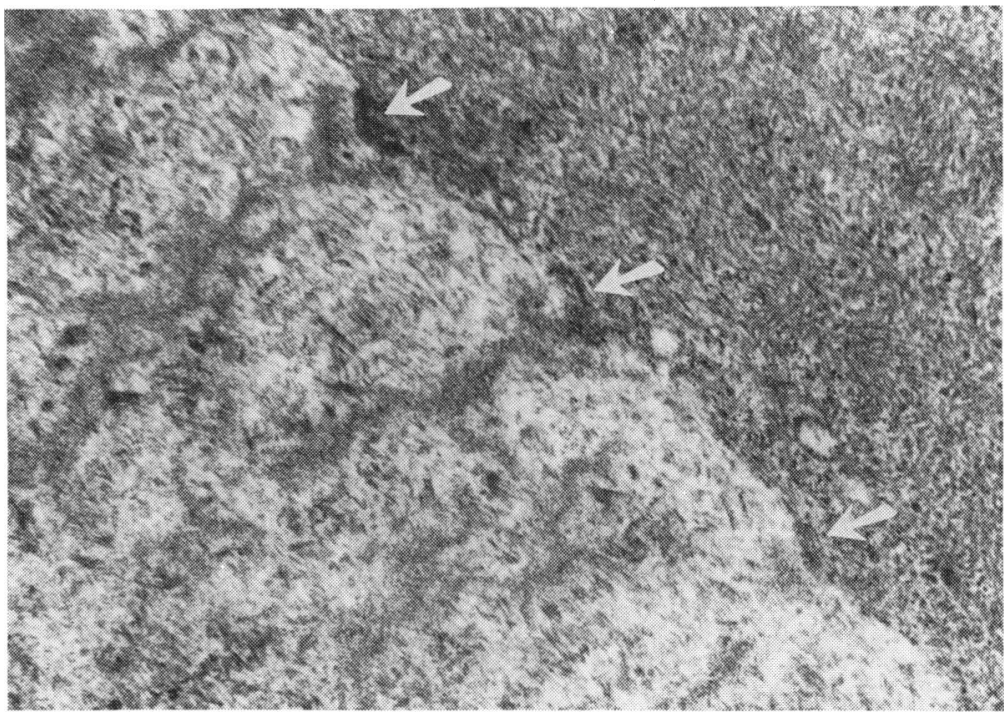

which fit them for their normal role as surface squames. Thereafter their programmed death is followed by autolysis and subsequent seclusion as microcysts. The microcysts move forward, probably through lacunae in the midepithelial lamina, and finally their contents erupt into the tear film. The morphological findings of the present study do not contradict this view of the pathogenesis of the microcysts, but it is equally possible that some other factor such as permeability characteristics of the intraepithelial lamina (which are unknown) may result in impaired metabolism of the deeper cells and so contribute to their premature death. Phagocytosis is not involved in the process of microcyst formation, the walls of the cysts being formed by adjacent cells which flatten and surround without engulfing the dying cells. Tripathi and Bron (1973) observed acantholysis of the pale cells as the first discernible sign of cell death, a finding confirmed here. Histochemical findings in the present study suggest that intercellular and surface accumulation of acid mucopolysaccharides may be an early sign of cell upset which precedes microcyst formation. It is of interest in this connection that Skerrow and Matoltsy (1974) found significant quantities of PAS positive glycoproteins in their chemical analysis of isolated desmosomes. These changes are suggestive of a metabolic lesion rather than simply a vicarious maturation due to impaired forward migration. Encystment is apparently followed by dehydration shrinkage and finally autophagic breakdown. Similar morphological observations on the formation of microcysts were made by Broderick et al. (1974) in their study of fingerprint dystrophy. A midepithelial sheet of basement-like material is not, however, a feature of fingerprint dystrophy or of the other conditions in which microcysts occur.

Subepithelial basement membrane material was seen in all sections studied and it is presumably present over most of the cornea. It consists of two

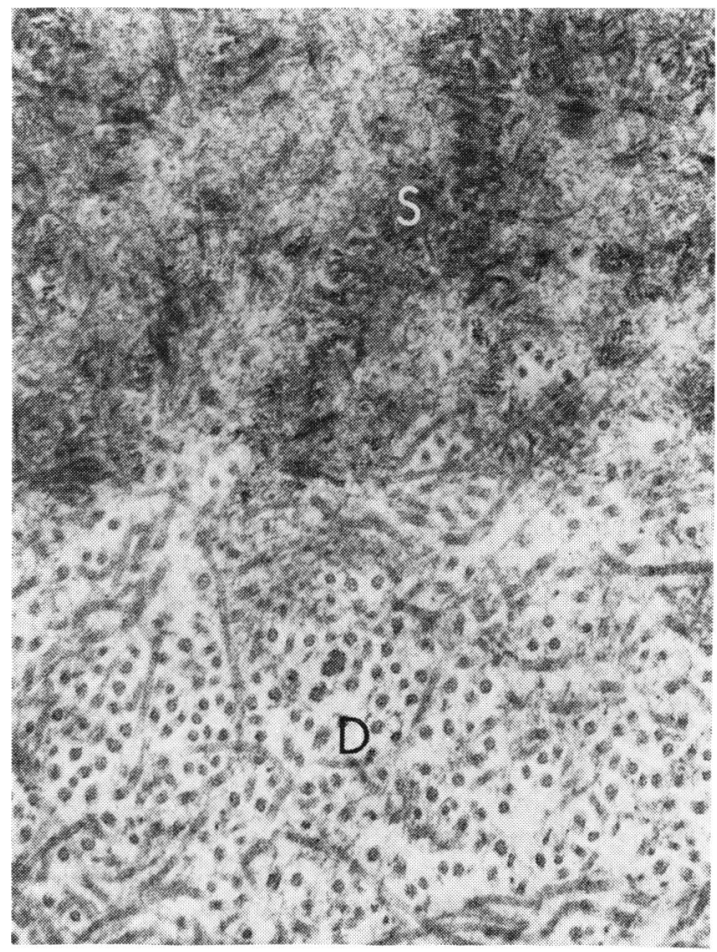

Fig. 10 Sharply defined junction of superficial, S, and deep layer, D, of subepithelial material $\times 44270$ 


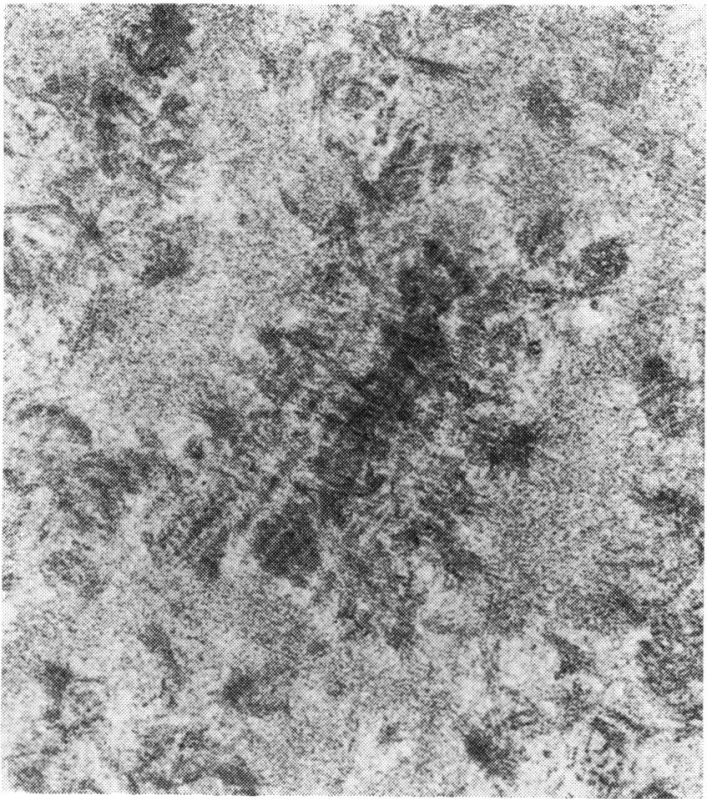

Fig. 11 Irregularly banded fibre in superficial part of subepithelial seam contains numerous laterally aggregated fibrils $8 \mathrm{~nm}$ wide embedded in fine granules $\times 88500$

layers. The first is a superficial zone containing fine granular material which is seemingly being synthesised in the vicinity of the hemidesmosomes. This material is compartmented like a sponge, in the cells of which lie peculiar banded fibrils reminiscent of those found by McTigue and Fine (1966) at the periphery of the normal cornea. In places villous projections extend from the basal cells into this layer. The deeper layer consists of banded fibrils which are presumably abnormal type IV collagens. Friability of the abnormal material lying beneath the corneal epithelium appears to be responsible for the ease with which epithelium may be surgically removed in this condition and it is probably the basis for recurrent erosions.

Aberrant basement membrane at the midepithelial level is continuous with the more superficial lamina of the two subepithelial layers and has a similar structure. Cells adjacent to this sheet of fibrogranular material are not otherwise identifiable as basal cells; moreover, hemidesmosomes and normal basement membrane are rarely discernible. This lamina of fibrogranular material appears to be the histological counterpart of the map-like nebulae seen with the slit lamp. The midepithelial extensions of the superficial layer of this basal seam may result from tangential forces causing buckling. Epithelial cells insinuating posterior to this layer go on dividing until the lamina breaks, allowing these cells and the microcysts to erupt into the tear film. Thus in places this layer is ruptured and the free ends curled back in a scroll doubtless corresponding with the biomicroscopic appearances of lacunae with rolled edges (Fig. 1).

Fine refractile lines resembling those seen in fingerprint dystrophy also lie at the midepithelial layer. They are apparently produced by invagination of the subepithelial seam and hence have a multi-

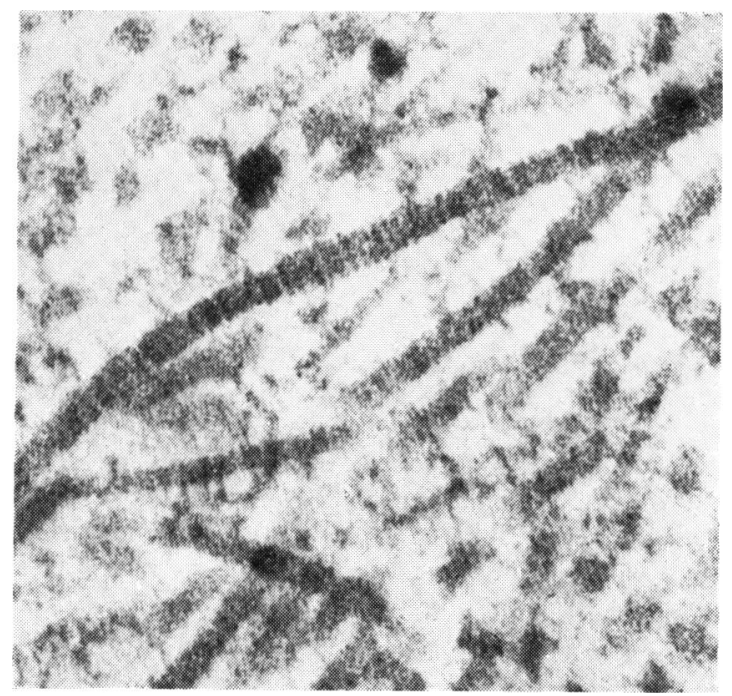

Fig. 12 Randomly orientated fibrils banded at $28 \mathrm{~nm}$ occupy the deep layer of the subepithelial seam $\times 120400$

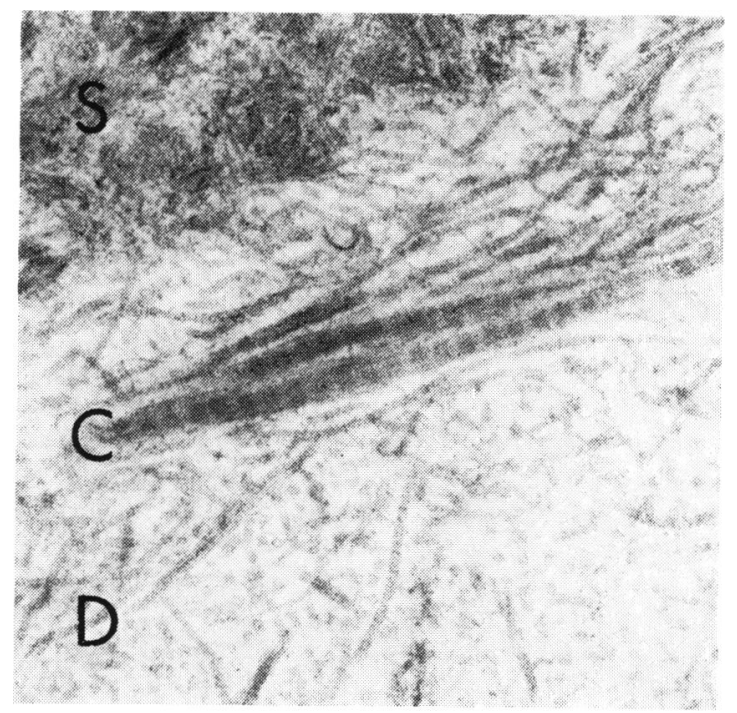

Fig. 13 Occasional bundles of collagen-like fibres, C, banded at $66 \mathrm{~nm}$ lie at the junction of the superficial, S, and deep, D, zones of subepithelial seam $\times 52500$ 
Table 1 Corneal epithelial diseases with microcysts and abnormal basement membrane production

\begin{tabular}{ll}
\hline 'Primary' & 'Secondary' \\
\hline Cogan's microcystic dystrophy & $\begin{array}{c}\text { H. simplex (Broderick and Dark, } \\
\text { 1976) }\end{array}$ \\
Meesmann's dystrophy & Trauma (Laibson, 1976) \\
Fingerprint/bleb dystrophy & $\begin{array}{l}\text { Fuchs's corneal dystrophy (Bron } \\
\text { and Tripathi, 1973) }\end{array}$ \\
& $\begin{array}{l}\text { Dysplasia of corneal epithelium } \\
\text { (Dark and Streeten, 1978, } \\
\text { unpublished observations) }\end{array}$ \\
\hline
\end{tabular}

laminar appearance in section. Laibson (1976) noted that they may be the sole manifestation of this disorder in members of some affected kinships. Moreover, since microcysts may occur in fingerprint dystrophy as observed by Broderick et al. (1974), Laibson (1976) was led to postulate that map nebulae, microcysts, and refractile striae are a spectral expression of the same fundamental disorder.

In contrast to this view of a continuum the present study serves to emphasise the differences between fingerprint and Cogan's dystrophy. Thus, the subepithelial seam and refractile striae in microcystic dystrophy consist of irregularly banded fibrils embedded in a fine granular matrix, in contrast to the granular ultrastructure of the striae and subepithelial seam seen in fingerprint dystrophy as described by Broderick et al. (1974) and the subepithelial seam in bleb dystrophy by Dark (1977). Biomicroscopically the striae in Cogan's dystrophy are visible in focal illumination as fine grey lines unlike those of the fingerprint disorder, which are visible only in retroillumination. Moreover, the large 'putty' cysts of Cogan's dystrophy, as pointed out by Bron and Tripathi (1973), have distinctive morphological and tinctorial properties which set them apart clinically from microcysts seen in a variety of other superficial disorders of the cornea of which Table 1 is an incomplete classification.

A consideration of the histological and cytological findings also serves to delineate the 'primary' disorders of this group. From the present study of Cogan's dystrophy the basic ultrastructural cell change appears to be hydropic cell degeneration, followed by shrinkage with intercellular accumulation of acid mucopolysaccharide (AMP). Fine and his co-workers (1977) have shown that in Meesmann's dystrophy autofluorescent AMP accumulates within both the cell and the abnormal subepithelial seam; moreover, the ultrastructural finding of a 'peculiar' fibrillogranular material in the cytoplasm is diagnostic of this disease. In fingerprint dystrophy Broderick et al. (1974) described cell shrinkage and the formation of multinucleated epithelial giant cells as the salient cytological changes. There is thus increasing evidence (Table 2) for tentatively regarding these 3 disorders as separate diseases.

It is a pleasure to acknowledge Miss Sharon Edward's responsibility for the technical aspects of electron microscopy in this study.

This study was supported by a grant from the Research Service of the Veterans Administration.

Table 2 Comparison of Cogan's, fingerprint/bleb, and Meesmann's dystrophies

\begin{tabular}{|c|c|c|c|}
\hline & Cogan & Fingerprint/Bleb & Meesmann \\
\hline Epithelial cytology & $\begin{array}{l}\text { Intracellular oedema, acantholysis, } \\
\text { intercellular accummulation of } \\
\text { AMP }\end{array}$ & $\begin{array}{l}\text { Acantholysis, cell shrinkage, } \\
\text { epithelial cell fusion }\end{array}$ & $\begin{array}{l}\text { Diagnostic accumulation of fibrillo- } \\
\text { granular material within cytoplasm }\end{array}$ \\
\hline \multicolumn{4}{|l|}{ Microcysts } \\
\hline Biomicroscopy & $\begin{array}{l}\text { Large }(20 \mu \mathrm{m} \text { to } 1 \mathrm{~mm}) \text { opaque } \\
\text { unstained with fluorescein }\end{array}$ & $\begin{array}{l}\text { Translucent or clear }(10 \text { to } 100 \mu \mathrm{m}) \\
\text { staining with fluorescein }\end{array}$ & $\begin{array}{l}\text { Small stained with fluorescein (10 to } \\
50 \mu \mathrm{m})\end{array}$ \\
\hline Histochemistry & $\begin{array}{l}\text { AMP positive. No autofluorescence. } \\
\text { PAS positive }\end{array}$ & $\begin{array}{l}\text { AMP positive.* No auto- } \\
\text { fluorescence.* PAS positive }\end{array}$ & $\begin{array}{l}\text { AMP positive. Autofluorescence. PAS } \\
\text { positive }\end{array}$ \\
\hline Ultrastructure & Loosely packed amorphous debris & Electron-dense masses & Homogeneous vacuolated substance \\
\hline \multicolumn{4}{|l|}{$\begin{array}{l}\text { Abnormal basement } \\
\text { membrane }\end{array}$} \\
\hline Biomicroscopy & $\begin{array}{l}\text { Visible direct and retro beam as } \\
\text { map nebulae and refractile striae }\end{array}$ & $\begin{array}{l}\text { Visible only in retroillumination as } \\
\text { fingerprint striae }\end{array}$ & Not observed \\
\hline Histochemistry & AMP negative. PAS positive & AMP negative. PAS positive & AMP positive. PAS positive \\
\hline Ultrastructure & Fibrogranular & Granular & Fibrogranular and granular \\
\hline
\end{tabular}

* Dark, A. J.. unpublished observations 


\section{References}

Bietti, G. B. (1965). Contribution à la connaissance des dégénérescences cornéennes seniles. Archives d'Ophtalmologie et Revue Générale d'Ophtalmologie, 25, 37-42.

Broderick, J. D., Dark, A. J., and Peace, G. W. (1974). Fingerprint dystrophy of the cornea: a histologic study. Archives of Ophthalmology, 92, 483-489.

Broderick, J. D., and Dark, A. J. (1976). Fingerprint striae of cornea following herpes simplex keratitis. Annals of Ophthalmology, 8, 481-484.

Bron, A. J., and Brown, N. A. (1971). Some superficial corneal disorders. Transactions of the Ophthamological Societies of the United Kingdom, 91, 13-29.

Bron, A. J., and Tripathi, R. C. (1973). Cystic disorders of the corneal epithelium, I. Clinical aspects. British Journal of Ophthalmology, 57, 361-375.

Cogan, D. G., Donaldson, D. D., Kuwabara, T., and Marshall, D. (1964). Microcystic dystrophy of the corneal epithelium. Transactions of the American Ophthalmological Society, 62, 213-225.

Cogan, D. G., Kuwabara, T., Donaldson, D. D., and Collins, E. (1974). Microcystic dystrophy of the cornea: a partial explanation for its pathogenesis. Archives of Ophthalmology, 92, 470-474.
Dark, A. J. (1977). Bleb dystrophy of the cornea: histochemistry and ultrastructure. British Journal of Ophthalmology, 61, 65-69.

Fine, B. S., Yanoff, M., Pitts, E., and Slaughter, F. D. (1977). Meesmann's epithelial dystrophy of the cornea. American Journal of Ophthalmology, 83, 633-642.

Guerry, D. (1965). Observations on Cogan's microcystic dystrophy of the corneal epithelium. Transactions of the American Ophthalmological Society, 63, 320-334.

Laibson, P. R., and Krachmer, J. H. (1975). Familial occurrence of dot (microscopic) map, fingerpint dystrophy of the cornea. Investigative Ophthalmology, 14, 397-399.

Laibson, P. R. (1976). Microcystic corneal dystrophy. Transactions of the American Ophthalmological Society, 74, 483-531.

Rodrigues, M. M., Fine, B. S., Laibson, P. R., and Zimmerman, L. E. (1974). Disorders of the corneal epithelium: a clinicopathologic study of dct, geographic and fingerprint patterns. Archives of Ophthalmology, 92, 475-482.

Skerrow, C. J., and Matoltsy, A. G. (1974). Chemical characterization of isolated desmosomes. Journal of Cell Biology, 63, 524-530.

Tripathi, R. C., and Bron, A. J. (1973). Cystic disorders of the corneal epitinelium. II. Pathogenesis. British Journal of Ophthaimology, 57, 376-390. 